2 would decrease $k$ still further, and here exists for the present an unsolved contradiction between experience and the theory in its present form.

Looking at this state of things, Herren Kundt and Warburg at Strasburg thought it advisable to investigate experimentally the simplest case which nature offers to us, viz, the case of a gas which, according to its chemical behaviour, is a monatomic one. Herr Baeyer pointed out to them that mercury gas was such a gas; they therefore undertook to determine the specific heat of mercury gas. Here a contradiction to the theory did not become apparent; the experiment has yielded exactly the value demanded by theory for a monatomic gas, viz., $K=\mathrm{I} \cdot 67$. Thus it is proved that the molecule of mercury gas, with regard to its thermal and mechanical properties, behaves exactly like a material point. It is hardly necessary to remark that, with regard to other properties, it is not at all necessary that the same molecule should behave like a material point. Thus, for instance, one glance at the spectrum emitted by incandescent mercury gas, which is crossed by many bright lines, shows us at once that the molecule of the same, with regard to the light it emits, does certainly not behave like a material point.

With regard to the way in which the experiment was conducted, we confine ourselves to the following remarks.

The $k$ for mercury gas was determined from the velocity of sound in this gas, and this was found by means of the method of dust figures, formerly described by Herr Kundt.* A glass tube A, closed at both ends, well dried and pumped perfectly free from air, contained a certain quantity of mercury, which had been carefully weighed, and a little silicic acid. Sealed to this tube was another one, $B$ (this a little narrower), in such a manner as to form the prolongation of A. A was placed in a four-fold box made of iron plates, which was heated by a series of Bunsen burners. This box also contained the great reservoir of an air thermometer, and, if observations were made at a temperature under $354^{\circ}$, several mercury thermometers besides. The end of $B$, projecting from the box, was sealed up, and over this end a long wide glass tube $D$ was placed, which was closed at one end and contained a little lycopodium.

If now, after the necessary regulation in the heating arrangements, the thermometers in the box showed equal and sufficiently elevated temperatures, the tube composed of $A$ and $B$ was sounded by friction to its third longitudinal tone; at the same time a reading of the air thermometer was taken, and the temperature of the air in $\mathrm{D}$ was noted down. The powders introduced then showed in tubes $\mathrm{A}$ and $\mathrm{D}$ the sound-waves in mercury gas and in air respectively, so that afterwards the lengths of these waves could be measured with the greatest accuracy.

Let us suppose

$i$ to be the length of the sound-wave in air,

$l^{\prime}$ the absolute temperature of ", in in $\mathrm{D}$, mercury.gas,

$t \quad, \quad, \quad$ of mercury gas in A,

$d=6.9783$ the density of mercury gas (air $=$ I),

$k$ - the proportion $\frac{c^{\prime}}{c}$ of the two specific heats for air.

$k^{\prime}$

Then we have

$$
\text { , , " , for mercury gas. }
$$

$$
k^{\prime}=k\left(\frac{l^{\prime}}{l}\right)^{2} \frac{t^{\prime}}{t} d .
$$

If $k$ for air was taken at $=\mathrm{r} 405$ according to Röntgen, then by seven definite experiments, at different degrees of saturation of the mercury vapour, and three different sets of apparatus being employed, it was found on the average that

$$
k^{\prime}=\mathrm{I} \cdot 67 \text {. }
$$

The results of the different experiments never deviated more than one per cent. from this value.

$$
\text { * See Nature, vol, xii, p. } 88 \text {. }
$$

If the specific heat $c$ at constant volume for air is taken as $=1$, then it follows that $c$ for mercury

$$
c=0.60 \text {. }
$$

W.

\section{AMONG THE CYCLOMETERS AND SOME OTHER PARADOXERS}

NO notes have been handed down of the conversation between Erskine and Boswell, whilst strolling in Leicester Fields, on squaring the circle. There is on record, however, Boswell's small joke, "Come, come, let us circle the square, and that will do us good."

The subject is one that has occupied the thoughts of some few from the earliest times of geometrical history, and there are some now fascinated by it at this date, when we have-

$$
\begin{aligned}
& \text { "on the lecture slate } \\
& \text { The circle rounded under female hands }
\end{aligned}
$$

With flawless demonstration."

Old Burton advises him that is melancholy to calculate spherical triangles, square the circle, or cast a nativity. A popular novelist ("Aurora Floyd," chap. iv.), describing one of her characters "who was an inscrutable personage to his comrades of the IIth Hussars," says he was, " according to the popular belief of those harebrained young men, employed in squaring the circle in the solitude of his chamber."

To say of a man that he is a circle-squarer will make an ordinary mathematician shrug up his shoulders and indicate expressively that there is, in his opinion, a screw loose somewhere. Having had some slight acquaintance with the writings of a few of the race forced upon us, we propose here to pass them under review, generally contenting ourselves with letting them speak for themselves, for thus shall we possibly most eftectually confute their absurdities, at least in the judgment of our mathematical readers.

De Morgan, the great exposer of circle-squarers, trisectors, et id genus onne, has, after Montucla, stated ("Budget of Paradoxes," p. 96) that there still exist three ideas in the heads of this race--(I) That there is a large reward offered for success; (2) that the longitude problem depends on that success; and (3) that the solution is the great end and object of Geometry. Some eight years ago we saw a letter from a Spanish Don of La Mancha, who offered to send an infallible method of squaring the circle ; and within the last four months an application came to us from Sweden, in which the author stated that he had heard that the London Mathematical Society had offered a prize for the trisection of angles, and as he had after long working at the problem obtained a solution, he was ready to transmit the same, but his organ of caution led him to fear lest his communication might get into improper hands, and so he wished to know to whom to send the aforesaid solution. We need hardly say that the Society, in this matter imitating the example of the French Academy of Sciences and of our own Royal Society, has declined to receive any communication upon either of the above-named subjects or upon that of the allied problem, the Duplication of the Cube. This decision was arrived at in consequence of a bulky mass of papers on the circle problem having been laid before the President in the end of 1871 . The author had previously submitted his papers to our own examination, and after some little perplexing we were able to indicate the point at which the author had tripped. We have heard nothing further of the solution, nor seen any of the elaborate figures since. We think it fair to state that we believe this cyclometer to have been an honest man and a good geometer. $\mathrm{He}$ had worked at the problem, off and on, some twenty years, and attacked it by the lunes of Hippocrates of Chios.

We have consulted the "Introductorium Geometricum" of Charles de Bovelles (Bovillus) in the 1503, 
1507 (?), and 15 IO-1517 editions; and also his "Géométrie Practique " in the 1549 and 1555 editions; and we are disposed to think that De Morgan (B. of P., pp. 3I, 32 ) is in error, possibly in this case following Montucla (for he says he has not seen the former work, and he makes no mention of the second), though all the copies of the "Introductorium" cited above contain the De Quadratura which De Morgan states that he has seen. Any how, all the constructions we have seen of Bovill'rs give $\sqrt{10}$, and not $3 \frac{1}{8}$. This will readily be seen from the following:-Bovillus inscribes a square in a circle, and then states that the quadrantal arc is equal to the line drawn from an angle of the square to the middle point of one of the opposite sides. In his "Géométrie" he says of Cusa (whose views De Morgan states him to have adopted) : "Il ha usé de dimensions infinies, lesquelles un géométrien ne cognoist, et ne confesseroit jamais estre possibles. Nonobstant, son invention est bonne et approuvee, tant par raison que par expérience." Nor do we find any account of his quadrature agreeing with that of a peasant labourer, but he states that he too had attempted the problem by another method (than that of Cusa), and not without success. Whilst standing on a bridge at Paris he noticed the carriage-wheels passing over the road; the fact that when the wheel has performed a revolution we have a straight line whose length equals the circumference of the wheel, suggested his solution to him, and on his return home he easily got his construction, which is this : Divide a radius of the circle into four equal parts, produce this radius through a fourth of its length ; join the extremity of this line with an extremity of the diameter at right angles to the radius, and with the point as centre and this distance as radius describe a circle; the portion of the tangent at the extremity of the selected radius cut off by this circle, be says, equals the semi-circumference. It will be seen that this is the same value as that given above. Bovillus, also, in a libellus de mathematicis supplementis (1509), gives a third construction, which leads to the same value.

Before leaving this writer we ought to state that he attributes the first construction we have given to his friend M. Achaire Barbel, a man "ingenious at new inventions of use in geometry." It is with considerable diffidence that we have ventured to go thus into detail, but it seems to us that De Morgan had fallen into error in the case of this early writer.

We propose now to take up the subject at the point where it is left in the "Budget," constantly regretting that the hand which so vigorously lashed the offenders in this line now lies cold. Here we must give place to that arch circle-squarer, Mr. James Smith. We shall deal tenderly, however, with his book, as we learn that he too has gone over to the majority and joined his former opponent. The book we have now before us is "Why is Euclid unsuitable as a Text-book of Geometry? This question answered and the Propositions of Euclid 8 and 13, Book VI., proved to be erroneous by Heterodox Geometry." (Motto-" Magna est veritas et prævalebit." London : Simpkin, Marshall, and Co., I87r.) The editor, whose name does not appear, in an address to the reader, states that Geometricus, a principal correspondent in the pamphlet, is "an intimate acquaintance and almost in daily communication with Mr. James Smith, the wellknown author," \&c. Geometricus became a convert to Mr. Smith's views. He has no niche in the "Budget:" were we not informed to the contrary, we should have been disposed to say that Geometricus and Mr. James Smith were one and the same person. The first fifteen pages are mainly devoted to a correspondence between Geometricus and the Rev. Dr. Jones, if that can be called a correspondence in which the writing on one side is copious and on the other confined to simple acknowledgments of receipts of letters.

The doctor was singled out for this honour in conse- quence of his having written an able pamphlet "On the unsuitableness of Euclid as a Text-book of Geometry." Geometricus was delighted at the appearance of this work, thinking now at last "here is a recognised mathematician, who has got out of the groove and who can see a geometrical truth by whomsoever propounded;" but alas! he is soon disappointed, and finds that, as in $\mathrm{Mr}$. Smith's experience, directly a mathematician is driven into a corner, he invariably gets out of it by pleading pressing engagements, want of time, \&c., " and so a great and important scientific truth-it may be-is born to blush unseen," \&c. He then sends James Smith's works (which we said above had converted himself), and now the redoubtable champion of " $\pi=3 \frac{1}{8}$ " himself descends into the arena, and must have given the doctor a pretty lively time of it, from the I 3 th of April to the Ioth of June, I $87 \mathrm{I}$, as he assails him in six long letters, with diagrams, occupying nearly thirty-three octavo pages of print. Much of what had been written in the "Athenzeum Budget of Paradoxes" is brought up and the Smithian value maintained, for though this incontrovertible solution "may not be adnitted by you or Clifford (alluding to Prof. Clifford's paper ' On an unexplained contradiction in Geometry,' read before the British Association), or any such like mathematicians of the present age, I can afford to bide my time and trust to posterity doing me justice."

This is the main portion of the pamphlet; there is, however, occasional sparring, both on the part of Geometricus and of Mr. Smith, with the editor of (and some writers in) the Mechanics Magazine. In an appendix a correspondent recommends J. S., "now poor De Morgan (who made you look so rediculous [sic]), has departed from this life, there are still some great men left-Prof. Sylvester. Try him, Smith ; if you convert that gentleman to your 38 , I will give in humbly." Similar advice is given by the same writer in a second letter. The whole book is provocative of much amusement, ancl is quite of a piece with J. Smith's previous writings.

At the time of writing the previous remarks, we were under the impression that the "Budget" had exposed "Cyclometry and Circle Squaring in a Nutshell, by a member of the British Association for the Advancement of Science." This we at once found was not the case when the pamphlet was lent us by a friend. As we have devoted sufficient attention to $M r$. Smith, we may shortly say that it is in octavo form, fortyfour pages, and contains letters written between 24 th October 1870 and January $187 \mathrm{I}$; that is, immediately preceding the earliest date in the work we have noticed above. The correspondents are A. E. M. (is this the E. M. of the "Budget"?) and S. B. J. This last is another signature, we find, for the pertinacious Smith, who has figured elsewhere as "Nauticus," and wherefore not as "Geometricus"? The "Budget," though it does not discuss this brochure individually, has well demolished it by anticipation.

The close of the work is of a prophetical cast. "It is more than sixty years ago since an astronomer of recognised authority--who repudiated the idea that I could solve the problem of 'squaring the circle'-said to me : ' $A$ bright day will have dawned on the astronomical world if ever the EXACT ratio of diameter to circumference in a circle shall be discovered. The day will arrive when it will be said : 'In the nineteenth century of the Christian era - that remarkable century of invention and discovery -darkness still overshadowed the mathematical world. Scientific truth is, and ever has been, a plant of slow growth, but Magna est veritas, \&c.'" It is to be hoped that the good man has not left his mantle behind, and that "Geometricus" and he were really one and the same.

Mr. John Davey Hailes has a place in the "Budget" (pp. 339, 340). He has not, so far as we know, touched upon the squaring of the circle, but possibly he is approaching that as the termination of his labours. We 
have before us five slips. The first addressed "To the Scientific of University College, London, I87I. The Curve a Progressing Wheel Curve. A wheel four feet diameter with a nail in its rim: when traversing forward, the nail will form a curve, and much longer than the circumference of the wheel. Query. How much longer? and what must be the DIAMETER of a circle-for a part of the said circle to sHOW THE SAID CURVE?" And then there follow two other geometrical questions, the one to

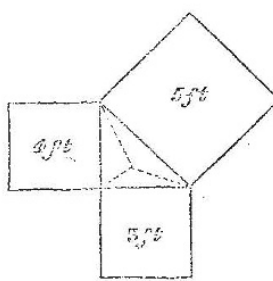
divide a trapezium into two equal parts. On the back is pasted (all in writing):" A Problem within a Problem. History record (sic) Pythagoras discovered the demonstration of the three squares to surround a Right Angle Triangle; the Two smallest when added together to equal the largest of twentyfive square Feet. I ask to find the Dimentions to demonstrate the Three Triangles dotted out into proportionaliy unequal parts, that when added to each square they produce the same result; viz. Two to equal the largest Figure.

"N.B.-From the Figures 3, 4, and 5,

They can be wrought perfective."

Dated Oct. 2, I87 I.

So far there is not much harm in J. D. H.

Another slip addressed, in ink, "To University College, London," is a bit of Hailesian Astronomy, and is, "Astronomy is Paradoxical." The N.B. is of interest in the light of the recent Transit Expeditions. "Those Transit of Venus measurers that try for the distance of the sun by Paxadox, are in error. Let them try to find the distance by demonstration. I say it can be done." The back of this page is devoted to "Astronomy and Longitude," and opens with the following doggrel :-

Science the Lock of Bible Truth, all the Works Divine,

Marnetic Key, unlock the Truth, and give true Mean Time.

In the Time of Joshua the Sun stood over Gibeon, the Moon over Azalon ;

It was at the Summer Solstice, 2548 from Adam, DISPROVE wHO CAN?

The Sun began to go back on the Dial of Ahaz at 40' past Noon.

This last line is in ink. We have then a rule to find true longitude at sea by time, sun, and moon. The spelling is a caution, and the calculation a fitting companion. This is dated Oct. 16 th, 1870 ; the former page Oct. 6th, 1871. Our last document from Mr. Hailes was sent to the British Association, 1868, and is entitled "My Calculated Time of Christ's Crucifixion, A.D. 30," with a number of dates: "And now I challenge all the astronomers in the world justly to dispute my above-given times for the above-given events." Verily, Mr. J. D. H. believes wisdom will die with him. Stand down! you will not do much harm, Mr. Hailes.

Mr. W. Upton, B.A. (B. of P., pp. 256-258) brought out in 1872 (E. and F. Spon), "The Circle Squared: Three famous Problems of Antiquity geometrically solved-I. The Quadrature or Circle Squared. 2. Diameter definitely expressed in terms of the circumference. 3. The circumference equalised by a right line. The whole rendered intelligible for arithmeticians as well as for geometers, and adapted for the higher classes in schools of both sexes, $F$ tate students, collegians, \&c." We think the day is not very near at hand when this subject will occupy the minds of schoolboys; the present generation have enough to do to secure time for the study of the elements in the "Conflict of Studies" which is being now waged. Mr. Upton, if now living, must be in his 83 rd year, and can hardly be expected to write much more on this subject. In his preface he acknowledges to previous failure with respect to the trisection, "but has it now complete." (De Morgan demolished his former essays; one we have seen appears to depend upon a construction familiar to practical geometers. The neatest of practical methods we believe to be that hit upon by J. J. Sylvester, F.R.S., recently referred to in the columns of NATURE.) His aim (in the quadrature) has been at practical utility, not rigidly subject to all the extreme niceties of mathematical strictness. The more general treatment he has not gone into on account of the expense (he has not apparently the purse of a James Smith or a "Kuklos") He pledges himself to the satisfactory fulfilment of all that the following advertisement sets forth :"I. The full development of the Quadrature, analytically and synthetically, in its threefold aspect-arithmetical, geometrical, and trigonometrical ; containing-2. The so greatly coveted and despaired of desideratum of equalising a circular segment by a rectilineal figure, which determines at once the complete solution of the Quadrature. 3. An appendix, with diagrams, \&c." All this to be pub. lished on or before Jan. I, 1873, or much sooner if a sufficiency of early subscription warrants it. This work we have not seen; we infer, then, that there were not found eighty subscribers of sufficient faith in Mr. Upton's word and sufficiently interested in the question to come down with the requisite $3 s, 6 d$. each. Wlat an opportunity for a liberal-ininded man! A trifle of $14 l$. in the one scale, and in the other a vexed question set at rest. Nor is this all; he could, too, satisfactorily account for the real origin and inspired nature of mythology, but for the present he confines himself to the more immediate subject. "Certain Hebrew letters and Greek mythology, nay, even Scripture itself, seem to bear distinct allusions to matters touching upon the origin of the square and circle." He winds up with a singular excursus upon the Hebrew "clistinctly representing the square and circle; the level line answering for base of the one and diameter of the other; the perpendicular for the adjoining side of the square; and the curve for a quadrant of the circle: each with an appearance of string at the extremity to intimate its being carried on to completion." There is a "Supplement" (diagram and five pages, free of charge), from which an estimate of the value of the work may be got on the author's own showing: "The precise difference is therefore not equivalent to the impression of a pin's point ; so that the author considers himself fully justified in looking upon the two areas as arithmetrcally equal. Moreover, in a geometrical solution, which is the real object of the problem, it is evident that so invisible a difference can have no possible effect."

Again, if he should be enabled to publish his proposed treatise, he can "show by three or four distinct but coricurrent proofs that the circle itself not only admits of, but-more surprising still-actually suggests the formation of a right-lined figure equal in area to the circular segment belonging to each quadrant! This is what may indeed be esteemed as the trae secret, the virtual key of the Quadrature; which the author will give to his readers and apply for them in the annexed diagram. He would have reserved the fact till he could have given it with the several proofs complete. But, as the fact itself, and its application to the diagram, ought to prove sufficient to produce conviction as to the truth of his assertion, he will proceed to apply it without further preface." We gather from his remarks that they turn upon the lengthening of a line by a point from a pencil which can make no perceptible difference in the geometrical construction. It seems only necessary to make this statement, and leave our mathematical readers to draw their own conclusions therefrom. (To be coninued.)

\section{INTERNATIONAL METEOROLOG ${ }^{*}$}

$\mathrm{T}$ may be truly said that all the large questions which fall within the province of meteorology can only be adequately discussed by data collected in accordance * Report of the Permanent Committee of the First International Congress at Vienna, for the year 1874 . Printed by authority of the Meteorological Committee. (London: Stanfurd, 1875 .) 